\title{
Efficacy of Actellic 300 CS-based indoor residual spraying on key entomological indicators of malaria transmission in Alibori and Donga, two regions of northern Benin
}

\author{
Albert Sourou Salako ${ }^{1,2^{*}}$, Fortune Dagnon ${ }^{3}$, Arthur Sovi ${ }^{1,4,5}$, Gil Germain Padonou ${ }^{1,2}$, Rock Aikpon $^{1,6}$, \\ Idelphonse Ahogni 1,2, Thomas Syme ${ }^{5}$, Renaud Govoétchan 1,4, Herman Sagbohan 1,2, \\ André Aimé Sominahouin ${ }^{1,7}$, Bruno Akinro ${ }^{1}$, Laurent lyikirenga ${ }^{8}$, Fiacre Agossa ${ }^{1,9}$ and Martin Codjo Akogbeto ${ }^{1}$
}

\begin{abstract}
Background: The current study shows the results of three years of IRS entomological monitoring (2016, before intervention; 2017 and 2018, after intervention) performed in Alibori and Donga, northern Benin.

Methods: Mosquito collections were performed on a monthly basis using human landing catches and pyrethrum spray catches in six districts including four treated with Actellic 300 CS (Kandi, Gogounou, Djougou and Copargo) and two untreated (Bembèrèkè and Kouandé) which served as control sites. Key transmission indicators of Anopheles gambiae (s.l.) as well as the residual activity of Actellic 300 CS assessed through WHO cone tests, were determined.

Results: The residual efficacy duration of Actellic 300 CS after the two IRS campaigns (2017 and 2018) was 4-5 months (May-September). The parity rate and the sporozoite index of An. gambiae (s.l.) were $36.62 \%$ and $0.71 \%$, respectively, after the first spray round in treated areas compared to $57.24 \%$ and $3.7 \%$, respectively, in the control areas $(P<0.0001)$. The same trend was observed after the second spray round. After the first spray round, each person received 1.6 infective bites/month (ib/m) in the treated areas against $12.11 \mathrm{ib} / \mathrm{m}$ in the control areas, resulting in a reduction rate of $86.78 \%$. Similarly, the entomological inoculation rate was $1.5 \mathrm{ib} / \mathrm{m}$ after the second spray round in the treated areas vs $9.75 \mathrm{ib} / \mathrm{m}$ in the control areas, corresponding to a reduction of $84.61 \%$. A decrease in the parity rate (46.26\%), sporozoite index (85.75\%) and EIR (87.27\%) was observed for An. gambiae (s.l.) after the first round of IRS (June-October 2017) compared to the pre-intervention period (June-October 2016). The density of An. gambiae (s.l.) ranged between $0.38-0.48$ per house in treated areas vs 1.53-1.76 An. gambiae (s.l.) per house respectively after the first and second IRS rounds.
\end{abstract}

Conclusions: This study showed the positive impact of IRS in reducing key entomological parameters of malaria transmission in Alibori and Donga. However, the considerable blood-feeding rate of An. gambiae (s.l.) in spray areas, stress the need for the population to sleep under long-lasting insecticidal nets (LLINs) in addition, to prevent from mosquito bites which did not succeed in resting on sprayed walls.

Keywords: IRS, Efficacy, Actellic 300CS, Malaria transmission, Benin

${ }^{*}$ Correspondence: albertsourousalako@yahoo.fr

${ }^{1}$ Centre de Recherche Entomologique de Cotonou (CREC), Cotonou, Benin

Full list of author information is available at the end of the article

c) The Author(s) 2019. This article is licensed under a Creative Commons Attribution 4.0 International License, which permits use, sharing, adaptation, distribution and reproduction in any medium or format, as long as you give appropriate credit to the original author(s) and the source, provide a link to the Creative Commons licence, and indicate if changes were made. The images or other third party material in this article are included in the article's Creative Commons licence, unless indicated otherwise in a credit line to the material. If material is not included in the article's Creative Commons licence and your intended use is not permitted by statutory regulation or exceeds the permitted use, you will need to obtain permission directly from the copyright holder. To view a copy of this licence, visit http://creativeco mmons.org/licenses/by/4.0/. The Creative Commons Public Domain Dedication waiver (http://creativecommons.org/publicdomain/ zero/1.0/) applies to the data made available in this article, unless otherwise stated in a credit line to the data. 


\section{Background}

Over the past decade, progress has been made in malaria control, through the promotion of indoor residual spraying (IRS) and long-lasting insecticidal nets (LLINs) [1-5]. Indeed, the proportion of the population with access to LLINs or having benefited from IRS in sub-Saharan Africa increased significantly from $2 \%$ in 2000 to $59 \%$ in 2014 [5]. According to the World Health Organization (WHO), of the 663 million malaria cases prevented in sub-Saharan Africa between 2001 and 2015 through vector control interventions, $79 \%$ were through LLINs and IRS [5]. This historic progress in the fight against malaria is partly due to the efforts of the USA Government through the President's Malaria Initiative (PMI) [6].

In Benin, IRS to control malaria vectors was introduced due to the expansion of pyrethroids resistance [7-10] which was the only insecticide class approved for the impregnation of LLINs. The strategy first implemented with bendiocarb (2008-2010) in the Oueme region (south Benin) and then, transferred to the Atacora region (north Benin) with the use of the same product (20112013) later replaced by pirimiphos-methyl (2014-2016), was very successful [11-13]. Indeed, Atacora region offers a good cost-effectiveness ratio insofar as a single IRS round is sufficient to cover its short transmission period, which favored the relocation of the intervention to that region. In addition, the decrease in susceptibility of mosquitoes to bendiocarb in the same region [14] has favored the switch from this insecticide to pirimiphosmethyl, which showed good performance in experimental huts trials [15].

After six years of IRS implementation in the Atacora region, the National Malaria Control Programme (NMCP), in agreement with various partners, decided to partially withdraw the intervention from some districts of this region and relocate it to two other regions (Alibori and Donga). This decision not only falls within the framework of the implementation of the national insecticide resistance management plan, but provides opportunity for coverage in two high burden regions [16] which have never benefitted from this intervention. In preparation for this relocation, prior studies have shown that $A n$. gambiae (s.l.), the main malaria vector in the two target regions $[17,18]$, was susceptible to pirimiphos-methyl $[19,20]$, an organophosphate insecticide and potential candidate for the IRS campaigns in Alibori and Donga.

In 2017 and 2018, all houses in Djougou, Copargo and Ouake (Donga region) and Kandi, Gogounou and Segbana districts in the Alibori region were treated with Actellic 300CS (pirimiphos-methyl). The present study shows the results of the IRS entomological monitoring conducted in both regions. Thus, the impact of the strategy on key entomological indicators of malaria transmission as well as, the residual efficacy duration of Actellic 300CS on the different type of sprayed walls were evaluated.

\section{Methods \\ Study area}

In 2017, Benin's NMCP relocated IRS to six districts of northern Benin, including three districts (Kandi, Gogounou and Segbana) in the Alibori region and three other (Djougou, Copargo, Ouake) in the Donga region (Fig. 1). A total of 1,226,161 and 1,287,469 persons were protected with Actellic 300 CS (pirimiphos-methyl) respectively in 2017 and 2018. For the entomological monitoring of the intervention, 4 districts were surveyed including Djougou $\left(09^{\circ} 42^{\prime} 10^{\prime \prime} \mathrm{N}, 01^{\circ} 40^{\prime} 55^{\prime \prime} \mathrm{W}\right)$ and Copargo $\left(09^{\circ} 50^{\prime} 19^{\prime \prime} \mathrm{N}, 01^{\circ} 32^{\prime} 39^{\prime \prime} \mathrm{W}\right)$ in northwest of Benin and, Kandi $\left(11^{\circ} 07^{\prime} 29^{\prime \prime} \mathrm{N}, 2^{\circ} 56^{\prime} 9^{\prime \prime} \mathrm{W}\right)$ and Gogounou $\left(10^{\circ} 50^{\prime} 30^{\prime \prime} \mathrm{N}, 2^{\circ} 50^{\prime} 20^{\prime \prime} \mathrm{W}\right)$ in northeast of the country (Fig. 1). Adjacent districts served as controls including Kouande $\left(10^{\circ} 19^{\prime} 54^{\prime \prime} \mathrm{N}, 1^{\circ} 41^{\prime} 29^{\prime \prime} \mathrm{W}\right)$ which is close to the IRS districts of Djougou and Copargo and, Bembereke $\left(10^{\circ} 13^{\prime} 30^{\prime \prime} \mathrm{N}, 02^{\circ} 40^{\prime} 05^{\prime \prime} \mathrm{W}\right)$ that is next to the IRS districts of Kandi and, Gogounou (Fig. 1).

The climate is Sudano-Guinean in the Donga region and Sudanese in the Alibori region. These two regions are dry savannah areas, with six months rainy season (midApril to mid-October) and a dry season which spans the remainder of the year. Overall, average annual rainfall ranges between 700-1200 $\mathrm{mm}$ and 1200-1300 in Alibori and Donga, respectively.

The incidence of simple and severe malaria in 2016 was $26.4 \%$ in Donga region and $13.3 \%$ in Alibori [16].

\section{Adult mosquito collections}

In each evaluation district, a central site and a peripheral site were selected. On each site, human landing catches (HLC) were conducted from 21:00 h to 5:00 h in 2 houses randomly selected at each field visit, with one collector sitting indoor and a second outdoor, amounting to a total of 4 collectors/hour/site and 8 collectors/hour/district over each sampling night. On each site, the 4 persons who collected the mosquitoes from 21:00 $\mathrm{h}$ to $1: 00 \mathrm{~h}$ were replaced by 4 other collectors from 1:00 h to 5:00 h. They were rotated between the different houses to avoid bias related to their ability to capture mosquitoes or, their individual attractiveness. This sampling method allowed to evaluate the humanbiting rate (HBR) of the Anopheles vectors, which were then analyzed by ELISA circumsporozoite protein (CSP) to determine their sporozoite index (SI). The morning collection (from 6:00 h to 7:00 h) of indoor resting mosquitoes using pyrethrum spray catch (PSC) was carried out in 20 houses per district (10 selected 

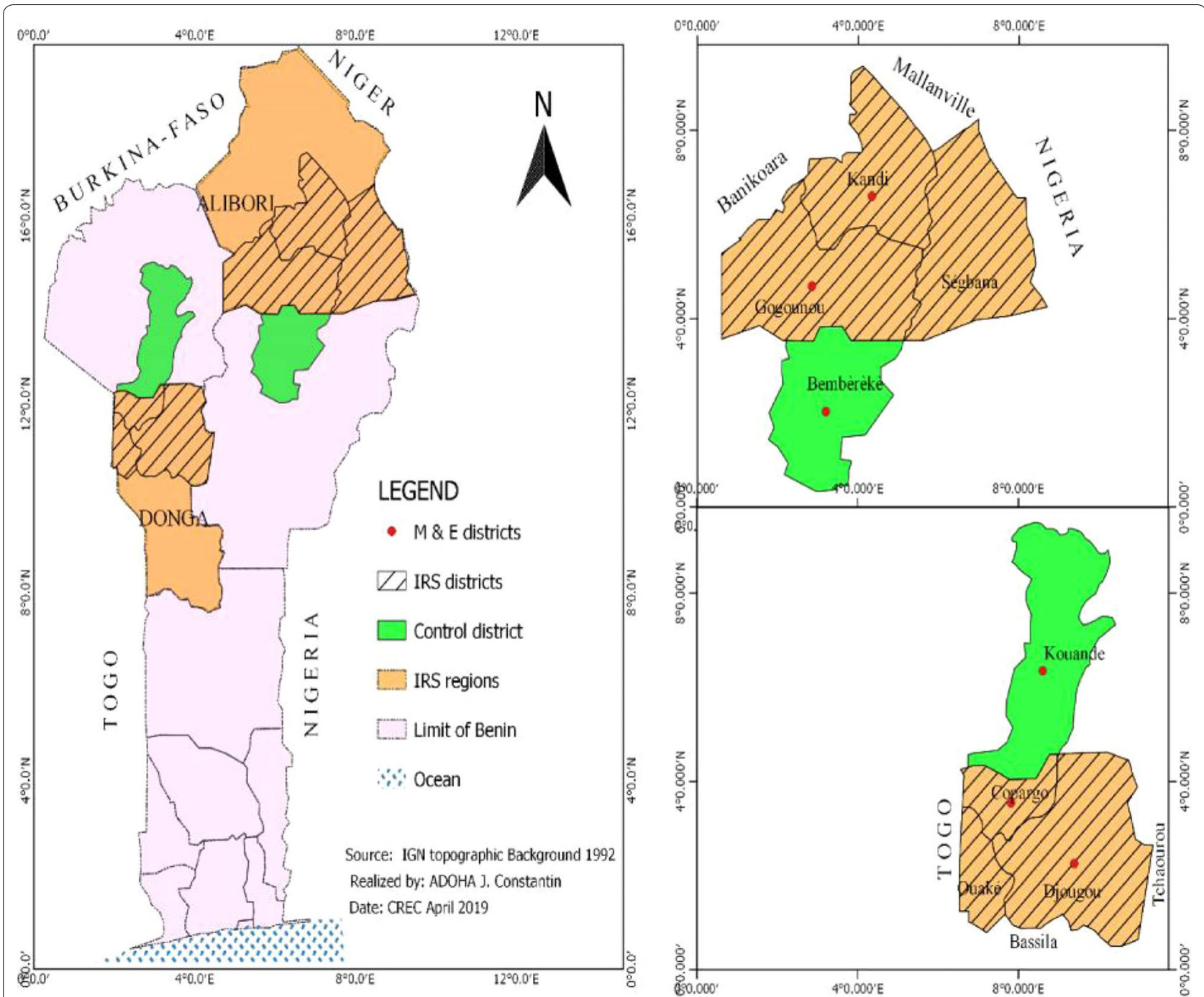

Fig. 1 Map of study area located within the northern region of Benin

from each central and peripheral site). This sampling technique allowed us to estimate the mean indoor vector density.

\section{Mosquito identification and processing Morphological identification of vectors species}

After each collection, mosquitoes were counted and morphologically identified using the taxonomic key of Gillies \& Meillon [21]. About $40-50 \%$ of the Anopheles vectors captured through HLC were dissected to assess their physiological age [22]. Those collected by PSC were classified according to the physiological state (unfed, feed, half-gravid and gravid) of their abdomen. Each specimen was then stored in a labeled Eppendorf tube containing silica gel and cotton for further molecular analyses.

\section{Molecular analyses}

To detect the presence of P. falciparum, heads and thoraces of all females An. gambiae (s.l.) were analyzed by ELISA CSP according to the protocol described by Wirtz et al. [23]. The abdomens, legs and wings of 20 to 50 specimens of An. gambiae (s.l.), randomly selected in each district each month, were analyzed by PCR according to the protocol of Santolamazza et al. [24], for molecular species identification.

\section{WHO cone bioassays}

The residual activity of Actellic $300 \mathrm{CS}$ on treated walls was evaluated after each IRS campaign using WHO cone bioassays [25]. These bioassays were carried out with females of An. gambiae Kisumu, a laboratory 
susceptible strain reared and maintained at the Centre de Recherche Entomologique de Cotonou (CREC).

\section{Cone bioassay procedure}

From 2017 to 2018, monthly cone bioassays [T0 (May), T1 (June), T2 (July), T2 (July), T3 (August), T4 (September), T5 (October) and T6 (November)] were conducted on treated walls of 20 houses randomly selected in the Donga and Alibori regions. The surfaces of the untreated walls were used as a control. These bioassays aimed not only to evaluate the quality of the treatment applications but also to monitor the residual effect of Actellic 300 CS on the treated walls. The bioassays were performed on the cement and mud walls encountered in the study area. Using a mouth aspirator, 15 females An. gambiae Kisumu aged $2-5$ days-old were carefully introduced into each cone, fixed at three different heights $(0.5 \mathrm{~m}, 1 \mathrm{~m}$ and $1.5 \mathrm{~m}$ ) of the treated walls. Mosquitoes were exposed to the sprayed walls for $30 \mathrm{~min}$; then removed from the cones and transferred to labeled sterile cups and provided with $10 \%$ sugar solution. After $24 \mathrm{~h}$ of observation at a temperature of $27 \pm 2{ }^{\circ} \mathrm{C}$ and a relative humidity of $80 \pm 10 \%$, the mortality rate was determined. When the control mortality was between 5-20\%, corrected mortality was performed accordingly using Abott's formula [26]; when the control mortality was higher than $20 \%$, the bioassay was considered invalid and repeated.

\section{Estimation of entomological parameters}

In this study, entomological parameters measured before (May 2016-April 2017) and after IRS (June 2017-August 2018) include: (i) human-biting rate (HBR), number of bites of An. gambiae (s.l.) per unit of time (HBR=No. of specimens of An. gambiae (s.l.) collected/No. of collectors/No. of nights of sampling); (ii) sporozoite index (SI), proportion of An. gambiae (s.l.) with circumsporozoite protein of $P$. falciparum ( $\mathrm{SI}=$ (No. of positive thoraces) Total no. of analyzed thoraces) $\times 100$ ); (iii) parity rate (PR), percentage of parous An. gambiae (s.l.) $(\mathrm{PR}=($ No. of parous mosquitoes/Total no. of dissected mosquitoes) $\times 100$ ); (iv) indoor vector density (IVD), mean number of An. gambiae (s.l.) collected per house (Total no. of An. gambiae (s.l.) collected indoors by PSC/Total no. of surveyed houses); (v) blood-feeding rate, proportion of An. gambiae (s.l.) having blood-fed [BFR $=$ (No. of bloodfed and half-gravid vectors collected by PSC/Total no. of vectors collected by the same method) $\times 100$ ]; (vi) entomological inoculation rate (EIR), level of malaria transmission by An. gambiae (s.l.) $(\mathrm{EIR}=\mathrm{HBR} \times \mathrm{SI})$.

\section{Data analysis}

Data were analyzed with the statistical $\mathrm{R}$ software, version 2.8. using the stats package [27]. The Poisson method was used to estimate and compare the confidence intervals of indoor vector density and EIRs of An. gambiae (s.l.) [28]. The Chi-square test of comparison of proportions was used to compare blood-feeding rate, sporozoite index, and parity rate of An. gambiae (s.l.). These different parameters were compared before and after IRS and then between the treated and control areas.

\section{Results \\ Residual effect of Actellic 300 CS on treated walls from 2017 and 2018}

Figure 2 shows the monthly variation of mortality rates in 2017 (Fig. 2a) and 2018 (Fig. 2b), after exposure of $A n$. gambiae Kisumu to cement and mud walls sprayed with Actellic 300CS in the districts of Djougou and Copargo. In 2017 and 2018, cone bioassays revealed full susceptibility (100\% mortality) of An. gambiae Kisumu to all sprayed walls (cement and mud), one-week post-IRS intervention (Fig. 2a, b). Overall, monthly data collected in 2017 and 2018 showed mortality rates of $\geq 80 \%$ (WHO efficacy threshold) between May and September/October regardless the district or the type of tested wall, giving an efficacy duration of 4-5 months (Fig. 2a, b).

\section{Vector species composition}

A total of 8776 Anopheles specimens belonging to seven species were collected through HLC over the study period in Alibori and Donga (treated areas from 2017), as well as in Bembereke and Kouande (control areas). Anopheles gambiae (s.l.) (98.05\%, 8605/8776) was the most abundant species found, followed by An. funestus (1.59\%, 140/8776). Only 15 An. pharoensis (0.17\%), 9 An. coustani (0.10\%), 5 An. ziemanni (0.05\%), 1 An. paludis and $1 A n$. nili (0.01\%) were collected (Table 1).

Of the 2774 specimens of An. gambiae (s.l.) analyzed by PCR over the whole study period, three sibling species [An. gambiae (65.60\%, $n=1820)$, An. coluzzii (33.42\%, $n=927)$ and $A n$. arabiensis $(0.98 \%, n=27)]$ were detected (Table 2). Overall, the same trend (predominance of $A n$. gambiae) was observed before and post-IRS in all localities (treated and control) (Table 2). Seasonal variation in the frequency of $A n$. gambiae and An. coluzzii was observed during the study (Fig. 3). Overall, out of a total of 628 mosquito specimens analyzed in the dry season, $77.7 \%(n=488)$ of $A n$. coluzzii were detected vs $22.3 \%$ ( $n=140$ ) of $A n$. gambiae. In contrast, in the rainy season, An. gambiae was predominant $(79.28 \%, 1680 / 2119)$ compared to An. coluzzii (20.72\%, 439/2119) (Fig. 3).

\section{Impact of IRS on the longevity of An. gambiae (s.I.)}

Overall, Table 3 and Fig. 4 show the impact of IRS on the longevity of $A n$. gambiae (s.l.) The parity rate of An. gambiae (s.l.) was $70.04 \%(996 / 1422)$ before IRS and $37.64 \%$ 

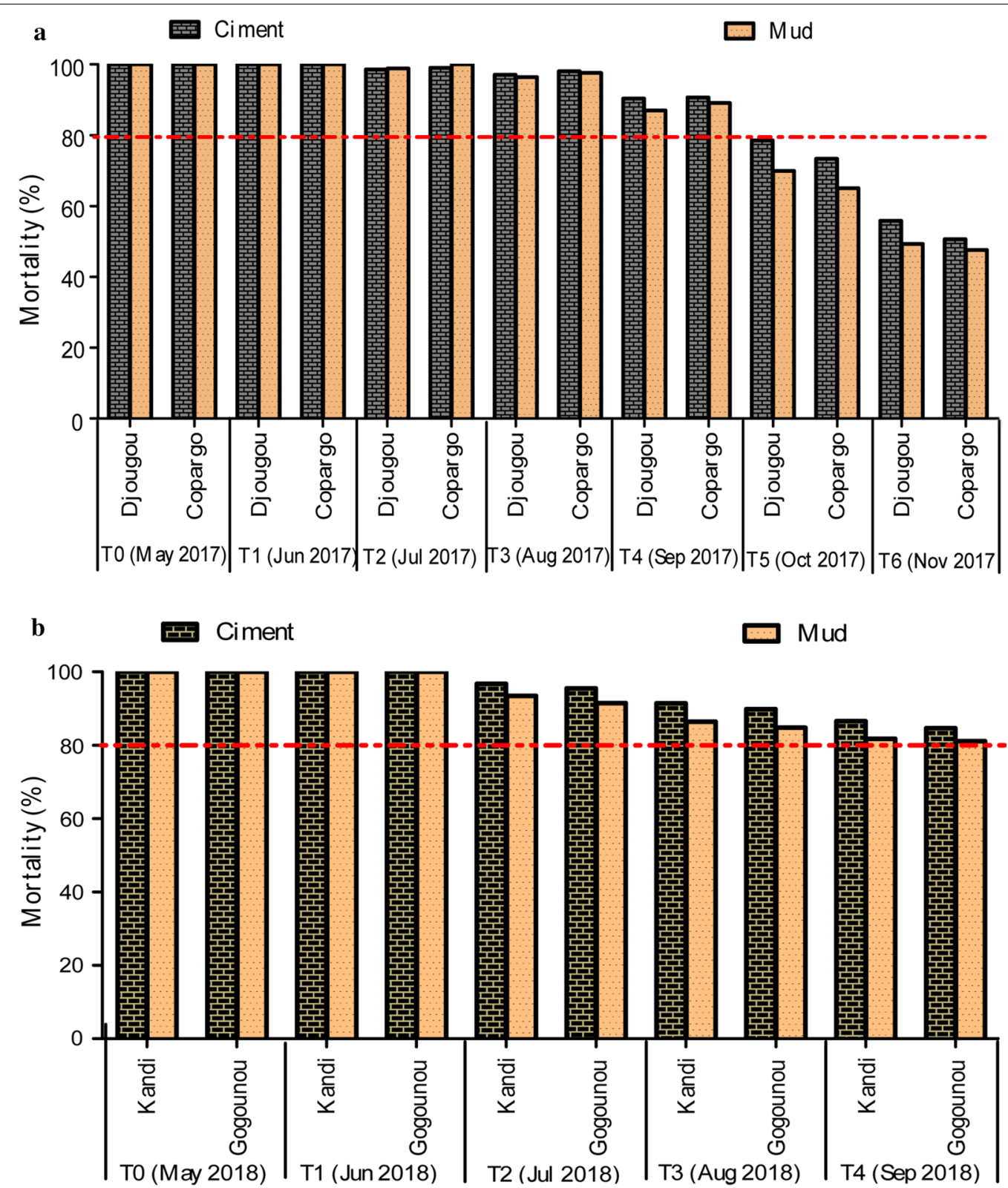

Fig. 2 Mortality rate of Anopheles gambiae Kisumu (laboratory susceptible strain) after 30 min exposure to cement and mud walls treated with pirimiphos-methyl in 2017 (a) and 2018 (b). The red line indicates the WHO efficacy threshold (mortality of 80\%) of an insecticide

(457/1214) after the first round of IRS in Alibori and Donga, equating to a $46.25 \%$ reduction in vector longevity $(P<0.0001)$ (Table 3$)$.

The trend was the same when comparing the parity rates obtained in the treated and control areas during the efficacy period of Actellic 300 CS. Indeed, between June and September, the parity rates of An. gambiae (s.l.) in the treated areas (Alibori and Donga) were $36.62 \%$ (364/994) in 2017 and 48.36\% (353/730) in 2018 against $57.24 \%(257 / 449)$ and $62.96(289 / 459)$ in the control areas $\left(\chi^{2}=52.798, d f=1, P<0.0001\right.$ for $2017 ; \chi^{2}=23.621$, $d f=1, P<0.0001$ for 2018) (Fig. 4).

Impact of IRS on the biting location of An. gambiae (s.l.)

Before IRS, the biting rate of An. gambiae (s.l.) was higher indoors [9.03 bites per person per night $(\mathrm{b} / \mathrm{p} / \mathrm{n})]$ than outdoors $(7.83 \mathrm{~b} / \mathrm{p} / \mathrm{n})(P=0.00098, R R=1.153$ (95\% CI: 1.06-1.26). Similarly, the biting activity of An. gambiae (s.l.) was more pronounced indoors than outdoors in the control areas after both the first $(13.04 \mathrm{~b} / \mathrm{p} / \mathrm{n}$ indoors $v s$ 
Table 1 Anopheles species composition in surveyed areas before and after IRS

\begin{tabular}{|c|c|c|c|c|c|c|}
\hline Species & $\begin{array}{l}\text { Before IRS (May } \\
\text { 2016-April 2017) }\end{array}$ & $\begin{array}{l}\text { After 1st round of IRS } \\
\text { (June 2017-March 2018) }\end{array}$ & $\begin{array}{l}\text { Control } \\
\text { (Bembereke, } \\
\text { Kouande) }\end{array}$ & $\begin{array}{l}\text { After 2nd round of IRS (June } \\
\text { 2018-November 2018) }\end{array}$ & $\begin{array}{l}\text { Control } \\
\text { (Bembereke- } \\
\text { Kouande) }\end{array}$ & Total \\
\hline An. gambiae (s.l.) & 2465 & 2379 & 1546 & 1286 & 929 & 8605 \\
\hline An. funestus & 54 & 54 & 16 & 9 & 7 & 140 \\
\hline An. coustani & 9 & 0 & 0 & 0 & 0 & 9 \\
\hline An. pharoensis & 3 & 2 & 5 & 2 & 3 & 15 \\
\hline An.paludis & 1 & 0 & 0 & 0 & 0 & 1 \\
\hline An. nili & 0 & 0 & 0 & 1 & 0 & 1 \\
\hline An. ziemanni & 2 & 2 & 0 & 1 & 0 & 5 \\
\hline Total & 2534 & 2437 & 1567 & 1299 & 939 & 8776 \\
\hline
\end{tabular}

8.58 outdoors; $R R=1.52$ (95\% CI: $1.35-1.72), P<0.0001$ ) and the second IRS rounds $(14.2 \mathrm{~b} / \mathrm{p} / \mathrm{n}$ indoors $v s 7.83$ outdoors; $R R=1.81$ (95\% CI: 1.58-2.09), $P<0.0001$ ) (Table 4). However, the opposite trend was observed after the first $(4.86 \mathrm{~b} / \mathrm{p} / \mathrm{n}$ indoors $v s 10.27$ outdoors; $R R=2.11$ (95\% CI: 1.91-2.34), $P<0.0001)$ and the second $(7.49$ $\mathrm{b} / \mathrm{p} / \mathrm{n}$ indoors $v s 8.03$ outdoors; $R R=1.07$ (95\% CI: $0.96-$ $1.2), P=0.233)$ rounds of IRS in the areas targeted by the strategy (Table 4).

\section{Impact of IRS on SI and EIR of An. gambiae (s.I.)}

A total of 8603 head-thoraces of $A n$. gambiae (s.l.) were analyzed by ELISA CSP over the study period. After the ELISA CSP tests, a mean SI of 8.4\% (95\% CI: 7.25-9.63\%; 181 positive samples out of 2158 tested) was obtained before IRS (June-October 2016) compared to 1.2\% (95\% CI: $0.8-1.8 \%$; 26 positive samples out of 2122 tested) after the first round of IRS (June-October 2017), corresponding to a reduction rate of $85.71 \%\left(\chi^{2}=117.69\right.$, $d f=1, P<0.0001)$. Similarly, an $87.27 \%$ reduction in EIR was observed after the first round of IRS (2.7 infective bites/person/month) as compared to the pre-intervention period (21.21 ib/p/month) in Alibori and Donga $(R R=7.83$ (95\% CI: 5.17-12.31), $P<0.0001)$ (Table 5).

This reduction in the SI and EIR of An. gambiae (s.l.) was also observed in the treated areas as compared to the control ones during the efficacy period of Actellic $300 \mathrm{CS}$ in 2017 and 2018. Indeed, after the first round of IRS (June-September 2017), a mean SI of 0.7\% (95\% CI: $0.36-1.2 \%$; 12 positive samples out of the 1697 tested) was obtained in the treated areas compared to 3.7\% (95\% CI: $2.7-5.01 \%$; 42 positive samples out of 1124 tested) in the control areas $\left(\chi^{2}=31.45, d f=1, P<0.0001\right)$ (Table 6). During the same period, a person received a mean 12.11 $\mathrm{ib} /$ month in control areas against $1.6 \mathrm{ib} / \mathrm{month}$ in the treated areas $(R R=7.53$ (95\% CI: $3.89-12.73), P<0.0001)$, which equals to an $86.78 \%$ reduction in malaria transmission. Moreover, the mosquitoes tested after the second
IRS round (June-August 2018) showed a mean SI of $0.64 \%$ (95\% CI: $0.27-1.2 \%$; 8 positive samples out of 1241 tested) in the treated areas against 3\% (95\% CI: $1.9-4.2 \%$; 26 positive samples out of 881 tested) in the control areas $\left(\chi^{2}=15.954, d f=1, P<0.0001\right)$ (Table 6). During the same period a significant reduction (84.61\%) in the EIR in the treated areas ( $1.5 \mathrm{ib} / \mathrm{p} / \mathrm{month}$ ) was observed compared to the control areas $(9.37 \mathrm{ib} / \mathrm{p} / \mathrm{month})(R R=6.25$ (95\% CI: 2.73-16.03), $P<0.0001$ ) (Table 6).

Figure 5 shows the dynamics of EIR from May 2016 to November 2018. The lowest EIRs were observed during the dry periods (January 2017 to April 2017 and November 2017 to March 2018) in both treated and control areas. After IRS implementation, lower monthly EIRs were observed in the treated areas compared to the control areas between June and October 2017 and 2018, which equals to 4 months of impact each year (Fig. 5).

\section{Impact of IRS on IVD in treated and control areas}

Table 7 shows the mean indoor density of An. gambiae (s.l.) before IRS and during Actellic 300 CS efficacy periods. Mean densities of 1.64 An. gambiae (s.l.) and 0.41 An. gambiae (s.l.) per room were recorded before (June-October 2016) and after (June-October 2017) IRS in Alibori and Donga, respectively, equating to a $75 \%$ reduction $(R R=4.04$ (95\% CI: 3.53-4.64), $P<0.0001)$ (Table 7). In addition, after the first IRS campaign (JuneSeptember 2017), 1.53 An. gambiae (s.l.) per room was recorded in control areas compared to 0.38 An. gambiae (s.l.) in treated areas, equating to a reduction of $75.16 \%$ $(R R=4.03$ (95\% CI: 3.34-4.88), $P<0.0001)$ (Table 7). The trend was the same after the second round of IRS (JuneAugust 2018) where a significant reduction of $72.72 \%$ in mean indoor density of An. gambiae (s.l.) in the treated areas (0.48 An. gambiae (s.l.) per room) compared to the control areas (1.76 An. gambiae (s.l.) per room) was observed $(R R=3.64 \quad(95 \%$ CI: 2.84-4.67), $P<0.0001)$ (Table 7). 


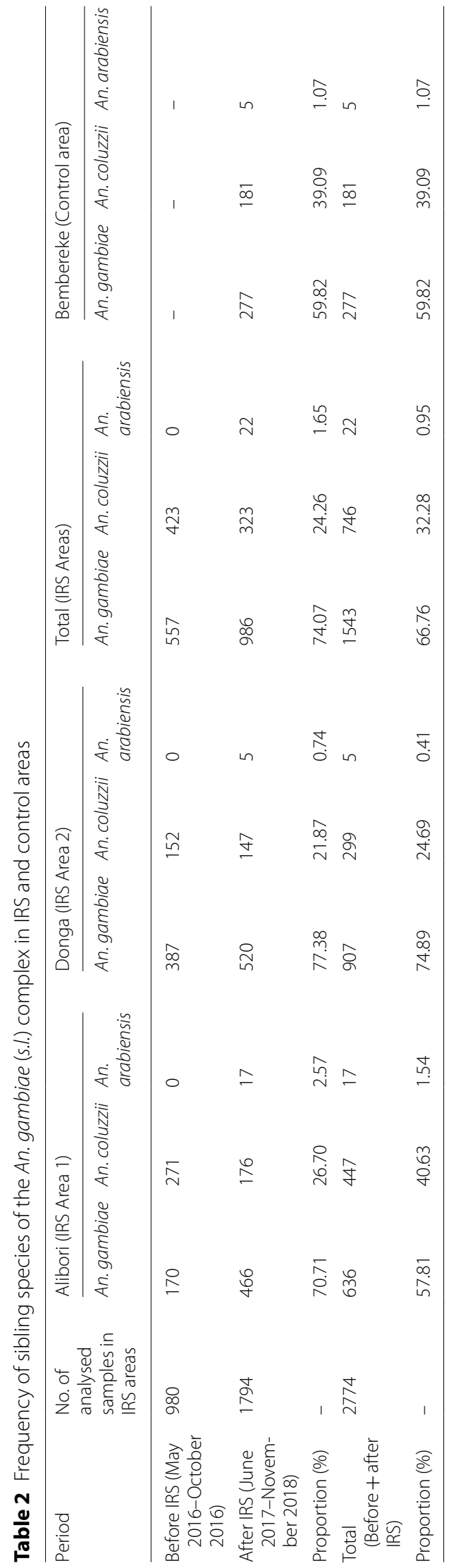




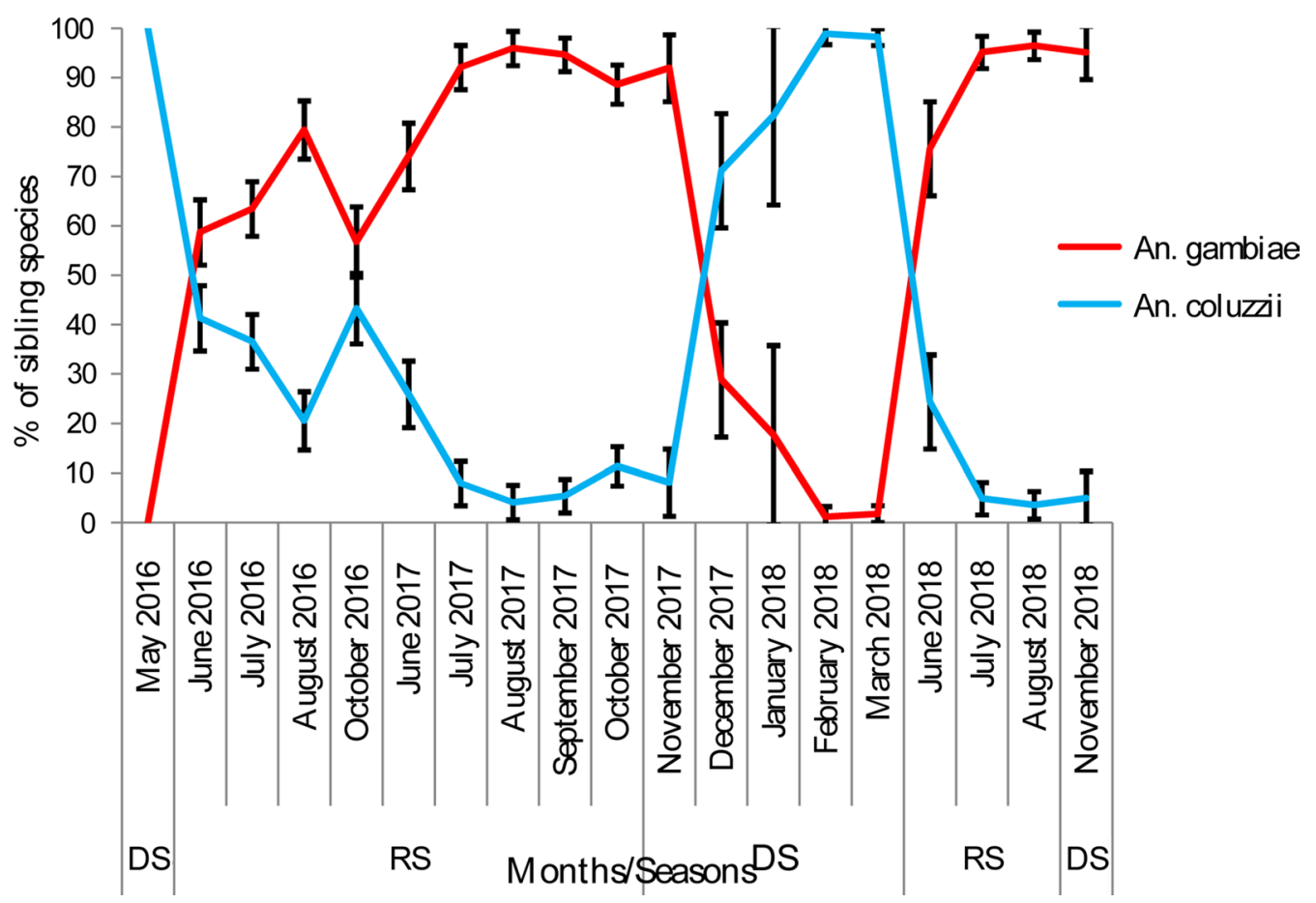

Fig. 3 Seasonal variation of sibling species (An. coluzzii and An. gambiae) in the study area. Abbreviations: DS, dry season; RS, rainy season

Table 3 Parity rates of Anopheles gambiae (s.l.) collected before and after the first round IRS

\begin{tabular}{llllll}
\hline IRS area & Variable & $\begin{array}{l}\text { Before IRS (June-October } \\
\text { 2016) }\end{array}$ & $\begin{array}{l}\text { After 1st round of IRS (June- } \\
\text { October 2017) }\end{array}$ & $X^{2}$-value & $P$-value \\
\hline Alibori-Donga & No. dissected & 1422 & 1214 & - & - \\
& No. parous & 996 & 457 & 37.64 & 276.57 \\
& Parous (\%) & 70.04 & $<0.0001$ \\
\hline
\end{tabular}

\section{Impact of IRS on blood-feeding rate of An. gambiae (s.I.) in treated districts}

Overall, blood-feeding decreased significantly after IRS intervention in the study regions. Prior to the intervention (June-October 2016), the blood-feeding rate of $A n$. gambiae (s.l.) was $96.20 \%$. After the first round of IRS (June-October 2017), this rate decreased to $63.37 \%$ in the treated areas, representing a reduction rate of $34.12 \%\left(\chi^{2}=236.03, d f=1, P<0.0001\right)$ (Table 8 ). Similarly, a $22.6 \%$ reduction in the bloodfeeding rate of $A n$. gambiae (s.l.) was also observed in the treated areas $(62.5 \%)$ compared to the control areas (80.74\%) during the Actellic $300 \mathrm{CS}$ persistence period (June-September 2017) $\left(\chi^{2}=17.76, d f=1, P<0.0001\right)$ (Table 8).

\section{Discussion}

The persistence of an insecticide applied to walls is one of the key indicators for determining the effectiveness of IRS $[29,30]$. In the Alibori and Donga regions, the persistence of Actellic $300 \mathrm{CS}$ used for the two IRS campaigns was 4-5 months (May-September/October). These results corroborate those obtained by Chanda et al. [31] in Zambia and Tchicaya et al. [32] in Mbe (Côte d'Ivoire) who observed a residual efficacy of Actellic $300 \mathrm{CS}$ of 4-5 months on mud and cement walls. However, persistence of Actellic 300 CS observed in this study is lower than that observed in Zanzibar ( 8 months) by Haji et al. [33] for the same product. These differences in community persistence of Actellic 300CS from one country to another could be due to the influence of several variable 


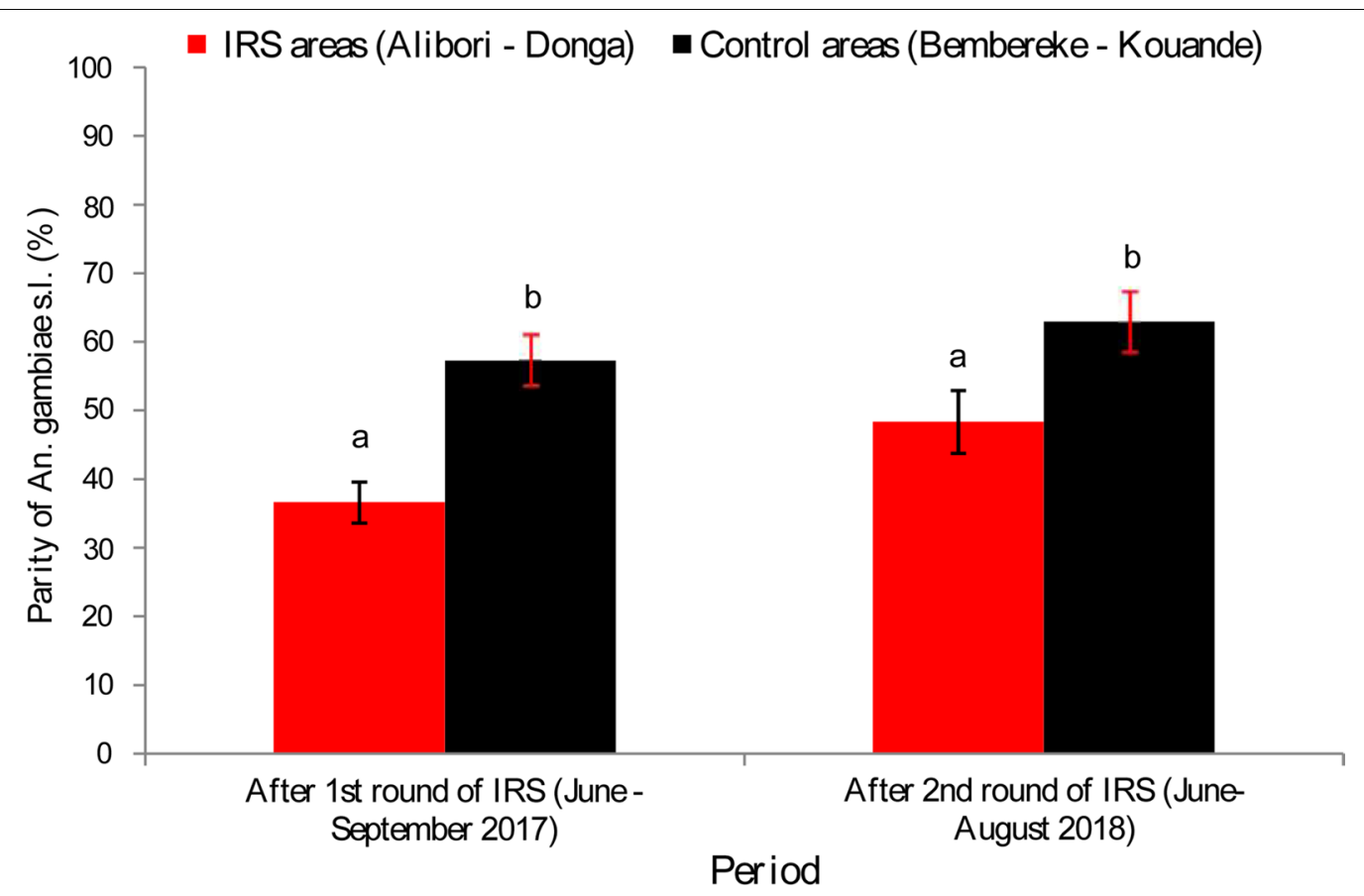

Fig. 4 Parity rate of Anopheles gambiae (s.l.) collected in treated and control areas

Table 4 Biting location of An. gambiae (s.I.) in IRS and control areas

\begin{tabular}{|c|c|c|c|c|c|c|}
\hline Period & Area & Location & No. collected & Person/night & $\operatorname{HBR}(\mathrm{b} / \mathrm{p} / \mathrm{n})$ & $P$-value \\
\hline \multirow[t]{2}{*}{ Before IRS (June-October 2016) } & \multirow[t]{2}{*}{ Future IRS } & Indoor & 1156 & 128 & 9.03 & \multirow[t]{2}{*}{0.00098} \\
\hline & & Outdoor & 1002 & 128 & 7.83 & \\
\hline \multirow[t]{4}{*}{ After 1st IRS round (June-September 2017) } & \multirow[t]{2}{*}{ IRS } & Indoor & 544 & 112 & 4.86 & \multirow[t]{2}{*}{$<0.0001$} \\
\hline & & Outdoor & 1150 & 112 & 10.27 & \\
\hline & \multirow[t]{2}{*}{ Control } & Indoor & 678 & 52 & 13.04 & \multirow[t]{2}{*}{$<0.0001$} \\
\hline & & Outdoor & 446 & 52 & 8.58 & \\
\hline \multirow[t]{4}{*}{ After 2nd IRS round (June-August 2018) } & \multirow[t]{2}{*}{ IRS } & Indoor & 599 & 80 & 7.49 & \multirow[t]{2}{*}{0.233} \\
\hline & & Outdoor & 642 & 80 & 8.03 & \\
\hline & \multirow[t]{2}{*}{ Control } & Indoor & 568 & 40 & 14.2 & \multirow[t]{2}{*}{$<0.0001$} \\
\hline & & Outdoor & 313 & 40 & 7.83 & \\
\hline
\end{tabular}

Abbreviations: HBR, human biting rate; $\mathrm{b} / \mathrm{p} / \mathrm{n}$, bite/person/night

Table 5 Human-biting rate, sporozoite index and entomological inoculation rate in Alibori and Donga regions (IRS areas) before and after the first round of IRS 2017

\begin{tabular}{lllll}
\hline Region & Variable & $\begin{array}{l}\text { Before IRS (June-October } \\
\text { 2016) }\end{array}$ & $\begin{array}{l}\text { After 1st round of IRS (June- } \\
\text { October 2017) }\end{array}$ & Reduction (\%) \\
\hline IRS areas (Alibori, Donga) & HBR/night & 8.43 & 7.37 & - \\
& SI (\%) & 8.4 & 1.2 & - \\
& EIR (ib/person/night) & 0.707 & 0.09 & - \\
& EIR (ib/person/month) & 21.21 & 2.7 & 87.27 \\
\hline
\end{tabular}

Abbreviations: $\mathrm{SI}$, sporozoite index; $\mathrm{HBR}$, human-biting rate; EIR, entomological inoculating rate; ib, infected bite 
Table 6 Human-biting rate, sporozoite index and entomological inoculation rate in IRS and control areas

\begin{tabular}{|c|c|c|c|c|c|c|}
\hline \multirow[t]{2}{*}{ Variable } & \multicolumn{3}{|c|}{ After 1st IRS campaign (June-September 2017) } & \multicolumn{3}{|c|}{ After 2nd IRS campaign (June-August 2018) } \\
\hline & $\begin{array}{l}\text { IRS areas } \\
\text { (Alibori-Donga) }\end{array}$ & $\begin{array}{l}\text { Control areas } \\
\text { (Bembereke-Kouande) }\end{array}$ & Reduction (\%) & $\begin{array}{l}\text { IRS areas } \\
\text { (Alibori-Donga) }\end{array}$ & $\begin{array}{l}\text { Control areas } \\
\text { (Bembereke-Kouande) }\end{array}$ & Reduction (\%) \\
\hline $\mathrm{HBR} /$ night & 7.56 & 10.81 & - & 7.76 & 11.01 & - \\
\hline SI (\%) & 0.71 & 3.7 & 80.81 & 0.6 & 3 & 80 \\
\hline EIR (ib/person/night) & 0.053 & 0.403 & - & 0.05 & 0.325 & - \\
\hline EIR (ib/person/month) & 1.6 & 12.11 & 86.78 & 1.5 & 9.75 & 84.61 \\
\hline
\end{tabular}

Abbreviations: SI, sporozoite index; HBR, human-biting rate; EIR, entomological inoculation rate; ib, infective bite

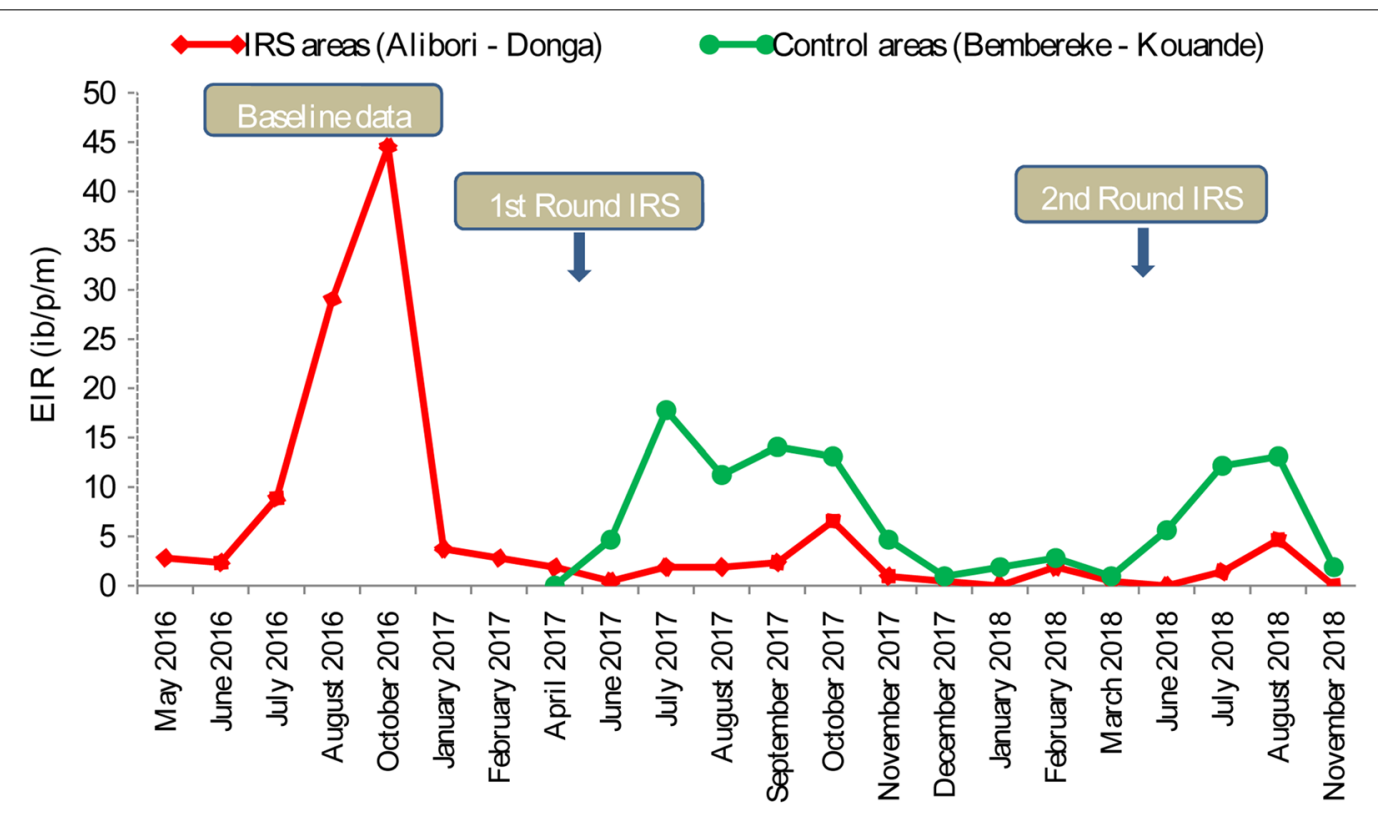

Months

Fig. 5 Dynamics of EIR before and after IRS campaigns in treated and control areas from May 2016 to November 2018

Table 7 Indoor density of An. gambiae (s.I.) in IRS and control areas

\begin{tabular}{|c|c|c|c|c|c|}
\hline Period & Area & No. of rooms & No. collected & Density/room & $P$-value \\
\hline Before IRS (June-October 2016) & Baseline & 610 & 1001 & 1.64 & $<0.0001$ \\
\hline After 1st round of IRS (June-October 2017) & After IRS areas & 673 & 273 & 0.41 & \\
\hline \multirow[t]{2}{*}{ After 1st round of IRS (June-September 2017) } & After IRS areas & 551 & 208 & 0.38 & $<0.0001$ \\
\hline & Control areas & 160 & 244 & 1.53 & \\
\hline \multirow[t]{2}{*}{ After 2nd round of IRS (June-August 2018) } & After IRS areas & 242 & 117 & 0.48 & $<0.0001$ \\
\hline & Control areas & 88 & 155 & 1.76 & \\
\hline
\end{tabular}

factors such as, the environmental conditions (temperature, relative humidity, exposure to ultraviolet rays) [34-38], the composition and characteristics (porosity and $\mathrm{pH}$ ) of treated walls [39-41] and/or the human interferences with treated surfaces (washing of treated walls) [42].
Two malaria vectors have been encountered in treated and control areas, An. gambiae (s.l.) (98.05\%), which represents the most predominant species, followed by $A n$. funestus (1.59\%). These data corroborate previous studies performed by Gnanguenon et al. [17] in Kandi (northeast Benin) and Aikpon et al. [43] in Atacora, a region 
Table 8 Blood-feeding rates in An. gambiae (s.l.) in treated and control areas

\begin{tabular}{|c|c|c|c|c|c|c|c|c|}
\hline Period & Area & No. collected & Unfed & Fed & Gravid & Half-gravid & $\begin{array}{l}\text { Blood- } \\
\text { feeding } \\
\text { rate } \%\end{array}$ & $P$-value \\
\hline Before IRS: June-October 2016 & IRS areas & 1001 & 26 & 922 & 12 & 41 & 96.20 & $<0.0001$ \\
\hline After 1st round of IRS: June-October 2017 & & 273 & 99 & 171 & 1 & 2 & 63.37 & \\
\hline \multirow[t]{2}{*}{ After 1st round of IRS: June-September 2017} & IRS areas & 208 & 78 & 129 & 0 & 1 & 62.5 & $<0.0001$ \\
\hline & Control areas & 244 & 16 & 187 & 31 & 10 & 80.74 & \\
\hline
\end{tabular}

neighboring Donga (northwest Benin). Molecular identification of the sibling species of the An. gambiae (s.l.) complex revealed that An. gambiae (65.60\%), An. coluzzii (33.42\%) and An. arabiensis (0.98\%) live in sympatry. The predominance of An. gambiae in the study area, particularly during rainy season, confirms that dry savannah areas where many temporary breeding sites are formed after rains, are conducive to the development this species. This was highlighted by previous studies carried out in similar bio-ecological areas in Nigeria [44], Cameroon [45] and Burkina Faso [46]. As previously found by Simard et al. [47] and Kudom et al. [48], the predominance of An. coluzzii in the dry season during this study could be due to the presence of permanent and semi-permanent breeding sites such as dams and, watering places that are the major larval habitats during this period. Deforestation and increasingly long dry seasons in the study area, are suspected to be unfavorable conditions for the development of $A n$. arabiensis, as reflected by the low number recorded in the present study $(n=27)$.

Overall, after the first round of IRS, significantly lower density, SI, blood-feeding and parity rates were observed compared to the pre-intervention period. Similarly, after the first and second rounds of IRS, levels of these indicators were significantly lower in treated areas compared to the control ones. Indeed, treated areas had probably become difficult to live in for the Anopheles vectors that fled treated houses. This observation is highlighted here by the low indoor resting density and the more pronounced outdoor biting rate of An. gambiae (s.l.) which were observed postIRS intervention in the targeted localities. Thus, only a small proportion of vectors could succeed in taking their blood meals inside treated houses as observed by Sy et al. [49] in west-central Senegal. The reduced blood-feeding rate of the vectors had certainly induced a lower parity rate in treated areas since success in taking a blood meal conditions the maturation of ovaries [50]. In addition, the lethal effect of Actellic 300 CS might not have favored incubation of parasite in vectors before they died, resulting in their low infectivity in the treated areas compared to the control areas. These results confirm the findings by Coleman et al.
[51] in northern Ghana and Mashauri et al. [52] in Lake Victoria basin of Tanzania, who also described a significant decrease in the SI of An. gambiae (s.l.) after IRS with Actellic 300 CS.

Before intervention, the EIR of An. gambiae (s.l.) was $21.21 \mathrm{ib} / \mathrm{p} / \mathrm{month}$ in Alibori and Donga. However, after the first round of IRS (June-October 2017), a substantial decrease to $2.7 \mathrm{ib} /$ person/month was detected, which represents a reduction of $87.27 \%$. The high decrease in EIR in sprayed areas compared to the control areas (86.78\% in 2017 and $84.61 \%$ in 2018) could be due to a high IRS coverage in treated areas (more than 91\% IRS coverage in 2017 and 92\% in 2018). Indeed, similar results were obtained in Zambia [31], Zimbabwe [53], Tanzania [52] and Uganda [54] where more than 85\% IRS coverage with Actellic 300 CS was achieved. In parallel, the results of an epidemiological study conducted in 2017 after IRS revealed that the decrease of EIR was accompanied by an $8 \%$ decrease of incidence among children under five years of age in the treated area of Donga [55]. EIR reduction (86.78\% in 2017 and $84.61 \%$ in 2018 ) in our study area is lower than that previously observed by Akogbéto et al. [11] (94.4\% in Oueme, southern Benin), Aikpon et al. [12] (99.24\% in Atacora, northwest Benin) and Sy et al. [49] (92.59\% in central-west Senegal).

Although blood-feeding rates and SI of Anopheles were significantly lower in the treated areas compared to the control areas, they remained considerable in these areas. This highlights the need to support IRS campaigns with information, education and communication campaigns to aware the population on the necessity of sleeping under LLINs, even in sprayed houses to avoid bites of mosquitoes which do not succeed in resting on walls due to the insecticide effect.

Currently, pirimiphos-methyl CS is the only product used in IRS in Benin due to the emergence of resistance of An. gambiae (s.l.) to bendiocarb and pyrethroids [14]. Since resistance is a dynamic phenomenon, its emergence to organophosphates over time cannot be ruled out. Considering this, the use of new generation insecticides such as SumiShield ${ }^{\circledR}$ 50WG and Fludora ${ }^{\circledR}$ Fusion which have a persistence of approximately 8 to 10 months $[56,57]$ and which have been recently approved by WHO, may be 
considered. This will allow covering the entire duration of malaria transmission (approximately 6 months) in the two surveyed regions.

The present study has some limitations. Indeed, the discontinuation of the cone bioassays in September 2018 when Actellic 300CS was still effective meant the exact persistence duration of the product could not be determined. Moreover, the mosquito collections which started at 21:00 h did not allow collecting information on early mosquito biting in the evening.

\section{Conclusions}

The reduction of key entomological indicators of malaria transmission in the treated regions shows the positive impact of the IRS programme. However, this strategy must be complemented with a high use of LLINs for greater effectiveness in vector control.

\begin{abstract}
Abbreviations
IRS: indoor residual spraying; PMI: President's Malaria Initiative; USAID: United States Agency for International Development; WHO: World Health Organization; LLIN: long-lasting insecticidal nets; NMCP: National Malaria Control Programme; ElR: entomological inoculation rate; HBR: human-biting rate; ELISA: enzyme-linked immunosorbent assay; PCR: polymerase chain reaction; CSP: circumsporozoite protein; HLC: human landing catch; SI: sporozoite index; PSC: pyrethrum spray catch; IVD: indoor vector density; WG: water dispersible granules; CS: micro-encapsulated formulation; CREC: Centre de Recherche Entomologique de Cotonou.
\end{abstract}

\section{Acknowledgements}

We are grateful to the President's Malaria Initiative which supported financially this study. We would also like to acknowledge Monica Patton, Patrick Condo, Peter Thomas, Irish Seth and Raymond Beach of CDC who provided technical support to the study and critically revised the manuscript.

\section{Authors' contributions}

ASS, FD, AS, LI, FA and MCA conceived the study. ASS, GGP, AS, RA and MCA participated in the design of the study. Entomologic data was collected by ASS, RA, IA, HS, ASS and bioassays and laboratory analysis was carried out by ASS and HS. ASS, GGP, AS and MCA drafted the manuscript. Statistical data analysis by BA, AS, LI, FD and FA. TS and MCA critically revised the manuscript for intellectual content. All authors read and approved the final manuscript.

\section{Funding}

This study was financially supported by the USA President's Malaria Initiative (PMI) through the United States Agency for International Development (USAID) Africa Indoor Residual Spraying Project (AIRS).

\section{Availability of data and materials}

Data supporting the conclusions of this article are included within the article. The data used and/or analyzed in this study are available from the corresponding author upon reasonable request.

\section{Ethics approval and consent to participate}

The protocol of this study was evaluated and approved by the Institutional Ethical Committee of CREC (IECC) (Grant No. IORG005698). The risk of voluntary mosquito collectors to suffer from malaria has been minimized by identifying them in their home village as they might already have protected immunity due to their prolonged exposure to mosquitoes. Prior to their involvement in this study, they gave their consent and have been trained so that they could collect mosquitoes before they bite them. They have all been vaccinated against yellow fever and were regularly monitored. In case of confirmed malaria, they were immediately taken to the team medical doctor and administered effective treatment.

\section{Consent for publication}

Not applicable.

\section{Competing interests}

The authors declare that they have no competing interests.

\begin{abstract}
Author details
${ }^{1}$ Centre de Recherche Entomologique de Cotonou (CREC), Cotonou, Benin. ${ }^{2}$ Faculté des Sciences et Techniques de I'Université d'Abomey-Calavi, Cotonou, Benin. ${ }^{3}$ USA President's Malaria Initiative, USA Agency for International Development, Cotonou, Benin. ${ }^{4}$ Faculty of Agronomy, University of Parakou, BP 123, Parakou, Benin. ${ }^{5}$ Disease Control Department, Faculty of Infectious \& Tropical Diseases, The London School of Hygiene and Tropical Medicine, Keppel Street, London WC1E 7HT, UK. ${ }^{6}$ Université Nationale des Sciences, Technologies, Ingénierie et Mathématiques, Abomey, Bénin. ${ }^{7}$ Faculté des Sciences Humaines et Sociales de I'Université d'Abomey-Calavi, Abomey-Calavi, Benin. ${ }^{8}$ PMI VectorLink Project, Abt Associates, Cotonou, Benin. ${ }^{9}$ PMI VectorLink Project, Abt Associates, Kinshasa, Democratic Republic of Congo.
\end{abstract}

Received: 8 August 2019 Accepted: 19 December 2019

Published online: 30 December 2019

References

1. Sharp BL, Kleinschmidt I, Streat E, Maharaj R, Barnes Kl, Durrheim DN, et al. Seven years of regional malaria control collaboration-Mozambique, South Africa and Swaziland. Am J Trop Med Hyg. 2007;76:42-7.

2. Kleinschmidt I, Schwabe C, Shiva M, Segura JL, Sima V, Mabunda SJ, et al. Combining indoor residual spraying and insecticide-treated net interventions. Am J Trop Med Hyg. 2009;81:519-24.

3. Chizema-Kawesha E, Miller JM, Steketee W, Mukonka VM, Mukuka C, Mohamed AD, et al. Scaling up malaria control in Zambia: progress and impact 2005-2008. Am J Trop Med Hyg. 2010;83:480-8.

4. Steketee RW, Campbell CC. Impact of national malaria control scale-up programmes in Africa: magnitude and attribution of effects. Malar J. 2010;9:299.

5. WHO. World malaria report 2015. Geneva: World Health Organization; 2015. https://www.who.int/malaria/publications/world-malaria-repor t-2015/report. Accessed 10 Oct 2019.

6. The President's Malaria Initiative. Ninth annual report to congress; 2015. https://www.pmi.gov/docs/default-source/default-document-library/ pmi-reports/pmi-ninth-annual-report-congress.pdf. Accessed 15 Sept 2019.

7. Chandre F, Manguin S, Brengues C, Dossou Yovo J, Darriet F, Diabate A, et al. Current distribution of pyrethroid resistance gene $(k d r)$ in Anopheles gambiae complex from West Africa and further evidence for reproductive isolation of Mopti form. Parassitologia. 1999;41:319-22.

8. Corbel V, N'Guessan R, Brengues C, Chandre F, Djogbenou L, Martin $\mathrm{T}$, et al. Multiple insecticide resistance mechanisms in Anopheles gambiae and Culex quinquefasciatus from Benin, West Africa. Acta Trop. 2007;101:207-16.

9. Yadouleton A, Asidi A, Djouaka R, Braïma J, Agossou C, Akogbeto M. Development of vegetable farming. A cause of the emergence of insecticide resistance in populations of Anopheles gambiae in urban areas of Benin. Malar J. 2009:8:103.

10. Djogbenou L, Pasteur N, Bio-Bangana S, Baldet T, Irish SR, Akogbeto M, et al. Malaria vectors in the Republic of Benin: distribution of species and molecular forms of the Anopheles gambiae complex. Acta Trop. 2010;114:116-22.

11. Akogbeto M, Padonou GG, Bankole HS, Gazard DK, Gbedjissi GL. Dramatic decrease in malaria transmission after large-scale indoor residual spraying with bendiocarb in Benin, an area of high resistance of Anopheles gambiae to pyrethroids. Am J Trop Med Hyg. 2011;85:586-93.

12. Aïkpon $R$, Sèzonlin $M$, Tokponon F, Okè M, Oussou O, Oké-Agbo F, et al. Good performances but short lasting efficacy of Actellic 50 EC indoor residual spraying (IRS) on malaria transmission in Benin, West Africa. Parasites Vectors. 2014;7:256.

13. Akogbeto MC, Aikpon R, Azondekon R, Padonou G, Osse R, Agossa FR, et al. Six years of experience in entomological surveillance of indoor 
residual spraying against malaria transmission in Benin: lessons learned challenges and outlooks. Malar J. 2015;14:242.

14. Aïkpon R, Agossa F, Ossè R, Oussou O, Aïzoun N, Oké-Agbo F, et al. Bendiocarb resistance in Anopheles gambiae s.l. populations from Atacora department in Benin, West Africa: a threat for malaria vector control. Parasites Vectors. 2013;6:192

15. Agossa F, Aikpon R, Azondekon R, Govoetchan R, Padonnou GG, Oussou $\mathrm{O}$, et al. Efficacy of various insecticides recommended for indoor residual spraying: pirimiphos-methyl, potential alternative to bendiocarb for pyrethroid resistance management in Benin, West Africa. Trans R Soc Trop Med Hyg. 2014;108:84-91.

16. Ministère de la Santé. Annuaire des statistiques sanitaires 2016. Cotonou: Direction de la Programmation et de la Prospective; 2017.

17. Gnanguenon V, Govoetchan R, Agossa FR, Osse R, Oke-Agbo F, Azondekon R, et al. Transmission patterns of Plasmodium falciparum by Anopheles gambiae in Benin. Malar J. 2014;13:444.

18. Salako AS, Ahogni I, Kpanou C, Sovi A, Azondekon R, Sominahouin AA, et al. Baseline entomologic data on malaria transmission in prelude to an indoor residual spraying intervention in the regions of Alibori and Donga, northern Benin, West Africa. Malar J. 2018;17:392.

19. Gnanguenon V, Agossa FR, Badirou K, Govoetchan R, Anagonou R, OkeAgbo $F$, et al. Malaria vectors resistance to insecticides in Benin: current trends and mechanisms involved. Parasites Vectors. 2015;8:223.

20. Salako AS, Ahogni I, Aikkpon R, Sidick A, Dagnon F, Sovi A, et al. Insecticide resistance status, frequency of L1014F Kdr and G119S Ace-1 mutations, and expression of detoxification enzymes in Anopheles gambiae (s.l.) in two regions of northern Benin in preparation for indoor residual spraying. Parasites Vectors. 2018;11:618.

21. Gillies MT, De Meillon B. The Anophelinae of Africa south of the Sahara. S Afr Inst Med Res. 1968;54:1-343.

22. Detinova TS, Gillies MT. Observations on the determination of the age composition and epidemiological importance of populations of Anopheles gambiae Giles and Anopheles funestus Giles in Tanganyika. Bull World Health Organ. 1964;30:23-8

23. Wirtz R, Zavala F, Charoenvit Y, Campbell G, Burkot T, Schneider I, et al. Comparative testing of monoclonal antibodies against Plasmodium falciparum sporozoites for ELISA development. Bull World Health Organ. 1987;65:39.

24. Santolamazza F, Mancini E, Simard F, Qi Y, Tu Z, della Torre A. Insertion polymorphisms of SINE200 retrotransposons within speciation islands of Anopheles gambiae molecular forms. Malar J. 2008;7:163.

25. WHO. Indoor residual spraying: use of indoor residual spraying for scaling up global malaria control and elimination. World Health Organization Global Malaria Programme. Geneva: World Health Organization; 2006. https://apps.who.int/iris/handle/10665/69386. Accessed 19 July 2019.

26. Abbott WSA. Method of computing of an insecticide effectiveness. J Econ Entomol. 1925:18:265-7.

27. R Core Team. R: a language and environment for statistical computing Vienna: R Foundation for Statistical Computing; 2018. https://www.Rproject.org/. Accessed 12 Dec 2019.

28. Rothman KJ. Epidemiology: an introduction. Oxford: Oxford University Press; 2012.

29. WHO. Implementation of the global malaria control strategy: report of a WHO study group on the implementation of global plan of action for malaria control 1193-200. WHO technical report series; Geneva: World Health Organization; 1993. http://apps.who.int/iris/bitstream/10665 /37106/1/WHO_TRS 839_eng.pdf. Accessed 25 Aug 2019.

30. WHO. Vector control for malaria and other vector mosquito-borne diseases: report of a WHO group: WHO technical report series; Geneva: World Health Organization; 1995. http://apps.who.int/iris/bitst ream/10665/41726/1/WHO_TRS_857.pdf. Accessed 10 Sept 2019.

31. Chanda E, Chanda J, Kandyata A, Phiri FN, Muzia L, Haque U, et al. Efficacy of Actellic 300 CS, pirimiphos-methyl, for indoor residual spraying in areas of high vector resistance to pyrethroids and carbamates in Zambia. J Med Entomol. 2013;50:1275-81.

32. Tchicaya ES, Nsanzabana C, Smith TA, Donze J, de HipsI ML, Tano Y, et al. Micro-encapsulated pirimiphos-methyl shows high insecticidal efficacy and long residual activity against pyrethroid-resistant malaria vectors in central Côte d'Ivoire. Malar J. 2014;13:332.

33. Haji AK, Thawer NG, Khatib BO, Mcha JH, Rashid A, Ali AS, et al. Efficacy, persistence and vector susceptibility to pirimiphos-methyl (Actellic ${ }^{\circledR}$
300CS) insecticide for residual spraying in Zanzibar. Parasites Vectors. 2015;8:628.

34. Hadaway AB, Barlow F. The residual action of two organo-phosphorus compounds and a carbamate in dried muds. Bull World Health Organ. 1963;28:69-76.

35. Crosby DG, Leitis E, Winterlin WL. Photodecomposition of carbamate insecticides. J Agric Food Chem. 1965;13:204-7.

36. Müller HM, Stan HJ. Thermal degradation observed with different injection techniques: quantitative estimation by the use of thermo labile carbamate pesticides. J High Res Chromatogr. 1990;13:759-63.

37. Santos RLC, da Silva Fayal A, Aguiar AEF, Vieira DBR, Povoa MM. Evaluation of residual effect of pyrethroids on anopheles in Brazilian Amazon. Rev Saude Publica. 2007:41:2.

38. Senneca O, Scherillo F, Nuuziata A. Thermal degradation of pesticides under oxidative conditions. J Anal Appl Pyrolysis. 2007;80:61-76.

39. Mulambalah CS, Siamba DN, Ngeiywa MM, Vulule JM. Targeted indoor insecticide and malaria control in the western highlands Kenya. J Infect Dis Immunity. 2011;3:50-8.

40. Etang J, Nwane P, Mbida JA, Piameu M, Manga B, Souop D, et al. Variations of insecticide residual bio-efficacy on different types of walls: results from community based trial in South Cameroon. Malar J. 2011;11:378.

41. Sibanda MM, Focke WW, Labuschagne FJ, Moyo L, Nhlapo N, Maity A, et al. Degradation of insecticides used for indoor spraying in malaria control and possible solutions. Malar J. 2011;10:307.

42. Dengela D, Seyoum A, Lucas B, Johns B, George K, Belemvire A, et al. Multi-country assessment of residual bio-efficacy of insecticides used for indoor residual spraying in malaria control on different surface types: results from program monitoring in 17 PMI/USAID supported IRS countries. Parasites Vectors. 2018:11:71.

43. Aïkpon R, Ossè R, Govoetchan R, Sovi A, Oké-Agbo F, Akogbéto MC. Entomological baseline data on malaria transmission and susceptibility of Anopheles gambiae to insecticides in preparation for indoor residual spraying (IRS) in Atacora, (Benin). J Parasitol Vector Biol. 2013;5:102-11.

44. Onyabe DY, Vajime CG, Nock IH, Ndams IS, Akpa AU, Alaribe AA, et al. The distribution of $\mathrm{M}$ and $\mathrm{S}$ molecular forms of Anopheles gambiae in Nigeria. Trans R Soc Trop Med Hyg. 2003;97:605-8.

45. Wondji C, Simard F, Fontenille D. Evidence for genetic differentiation between the molecular forms $\mathrm{M}$ and $\mathrm{S}$ within the Forest chromosomal form of Anopheles gambiae in an area of sympatry. Insect Mol Biol. 2002;11:11-9.

46. Dabire KR, Diabate A, Namountougou M, Toe KH, Ouari A, Kengne P, et al. Distribution of pyrethroid and DDT resistance and the L1014F kdr mutation in Anopheles gambiae s.l. from Burkina Faso (West Africa). Trans R Soc Trop Med Hyg. 2009;103:1113-20.

47. Simard F, Ayala D, Kamdem G, Pombi M, Etouna J, Ose K, et al. Partage de niche écologique entre les formes moléculaires d'Anopheles gambiae s.l. au Cameroun: l'aspect écologique de la spéciation. BMC Ecol. 2009;9:17.

48. Kudom AA. Écologie larvaire d'Anopheles coluzzii à Cape Coast, Ghana: qualité de l'eau, nature de l'habitat et implications pour le contrôle des larves. Malar J. 2015;14:447.

49. Sy O, Niang EA, Ndiaye M, Konaté L, Diallo A, Ba E, et al. Entomological impact of indoor residual spraying with pirimiphos-methyl: a pilot study in an area of low malaria transmission in Senegal. Malar J. 2018;17:64.

50. Beklemishev WN. Le cycle gonotrophique, principe de base de la biologie d'Anopheles. Vop Fiziol Ekol Malar Komara. 1940;1:3.

51. Coleman S, Dadzie SK, Seyoum A, Yihdego Y, Mumba P, Dengela D, et al. A reduction in malaria transmission intensity in northern Ghana after 7 years of indoor residual spraying. Malar J. 2017;16:324.

52. Mashauri FM, Manjurano A, Kinung'hi S, Martine J, Lyimo E, Kishamawe $C$, et al. Indoor residual spraying with micro-encapsulated pirimiphosmethyl (Actellic ${ }^{\circledR}$ 300CS) against malaria vectors in the Lake Victoria basin, Tanzania. PLoS ONE. 2017;12:e0176982.

53. Kanyangarara M, Mamini E, Mharakurwa S, Munyati S, Gwanzura L, Kobayashi T, et al. Reduction in malaria incidence following indoor residual spraying with Actellic 300 CS in a setting with pyrethroid resistance: Mutasa District, Zimbabwe. PLoS ONE. 2016;1 1:e0151971.

54. Tugume A, Muneza F, Oporia F, Kiconco A, Kihembo C, Kisakye AN, et al. Effects and factors associated with indoor residual spraying with Actellic 300 CS on malaria morbidity in Lira District, northern Uganda. Malar J. 2019;18:44. 
55. Ogouyèmi-Hounto $A$, Hounkpe $B$, Savi de Tove YS, Edah E, Houngbegnon , Koukpoliyi A, et al. Effect of indoor residual spraying on malaria incidence, parasitemia and parasite density among children less than five years of age in northern Benin. J Parasitol Vector Biol. 2018;10:129-37.

56. Agossa FR, Padonou GG, Koukpo CZ, Zola-Sahossi J, Azondekon R, Akuoko OK, et al. Efficacy of a novel mode of action of an indoor residual spraying product, SumiShield ${ }^{\circledR}$ 50WG against susceptible and resistant populations of Anopheles gambiae (s.l.) in Benin, West Africa. Parasites Vectors. 2018;11:293.

57. Agossa FR, Padonou GG, Fassinou AJYH, Odjo EM, Akuoko OK, Salako $A$, et al. Small-scale field evaluation of the efficacy and residual effect of Fludora ${ }^{\circledR}$ Fusion (mixture of clothianidin and deltamethrin) against susceptible and resistant Anopheles gambiae populations from Benin, West Africa. Malar J. 2018;17:484.

\section{Publisher's Note}

Springer Nature remains neutral with regard to jurisdictional claims in published maps and institutional affiliations.
Ready to submit your research? Choose BMC and benefit from:

- fast, convenient online submission

- thorough peer review by experienced researchers in your field

- rapid publication on acceptance

- support for research data, including large and complex data types

- gold Open Access which fosters wider collaboration and increased citations

- maximum visibility for your research: over $100 \mathrm{M}$ website views per year

At BMC, research is always in progress.

Learn more biomedcentral.com/submissions 